\title{
Elementos para una caracterización semio- discursiva y narrativa de los relatos de viajes publicados en la revista Le Tour du Monde (1860- 1914): un análisis estructural del relato "Viaje en la Patagonia" (1900) del Conde Henry de la Vaulx*
}

\author{
Eduardo Gallegos Krause ${ }^{* *}$
}

\section{Resumen}

A través de la aplicación de un modelo semiótico estructural del texto, este trabajo da cuenta de los elementos narrativos y discursivos presentes en los relatos de viajes, específicamente en los publicados en la revista Le Tour du Monde. Asimismo presenta un análisis del relato del Conde Henry de la Vaulx titulado "Viaje en la Patagonia", publicado en la revista. Los resultados dan cuenta de la contradicción del viajero en cuanto a su auto-afirmación de "civilizado" y se demuestra, el fracaso del expansionismo civilizatorio.

Palabras clave: Relato de viaje, revista Le Tour du Monde, semiótica narrativa-discursiva, civilización/barbarie.

\section{An element for a discursive and narrative's semiotic of travel logs published in the magazine Le Tour du Monde (1860- 1914): structural analysis of the story of Count Henry de la Vaulx entitled "Journey in Patagonia" (1900)}

\begin{abstract}
Through a structural semiotic analysis of the text, this paper recounts narrative and discursive elements present in travel logs, specifically those published in the magazine $L e$ Tour du Monde. It also presents an analysis of the story of Count Henry de la Vaulx entitled "Journey in Patagonia" and published in this magazine. The analysis of this story realizes the contradiction of the traveler in terms of self-affirmation of "civilized" and it shows, the failure of civilization expansionism.
\end{abstract}

El presente artículo aborda algunos de los resultados de la investigación titulada «Voyageurs français et l'Amérique Méridional à la fin du XIXéme siècle. La représentation de làltérité indigène dans les récits de voyage de la revue Le Tour du Monde» realizada en el marco de la obtención de diploma C.E.P. en el Institute d'Etudes Politiques (IEP) de Rennes, Francia.

Chileno. Magíster en Ciencias de la Comunicación. Universidad de la Frontera, Temuco, Chile. Estudiante de Doctorado en Comunicación, Universidad de La Frontera - Universidad Austral, Chile. egallegoskrause@gmail.com. 
Keywords: Travel log, Le Tour du Monde magazine, Narrative-discursive semiotic, civilization/barbarism, discursive semiotic.

\section{Introducción}

La semiótica narrativa, conocida también como narratología, semiótica actancial y otras denominaciones, tiene como punto de partida la revalorización de los trabajos de análisis estructural realizados por Vladimir Propp (Morfología del cuento, 1981) sobre los cuentos de hadas rusos. Así, esta disciplina comenzó un camino evolutivo que llevó a un amplio desarrollo teórico y metodológico a mediados de la centuria pasada, teniendo como punto de mayor auge las décadas del sesenta y el setenta con los trabajos de Algirdas Greimas (1973, 1980), Claude Bremond (1964, 1966), Zvetan Todorov (1971), Roland Barthes (1966), y una larga lista de autores conglomerados sobre todo en Francia.

La premisa fundamental del análisis narratológico tiene que ver con la búsqueda de las leyes que rigen el universo narrado (Bremond, 1966). Para esto, se considera el texto como constituido por componentes diferenciados, los cuales se revisarán más adelante.

El presente trabajo persigue dos objetivos; el primero genérico, pues da cuenta de algunos elementos para una caracterización estructural de los relatos de viajes, sobre todo aquellos publicados en la revista francesa Le Tour du Monde, y que ya han sido objeto de análisis previos ${ }^{1}$. El segundo objetivo, de orden más específico, busca analizar el relato particular del conde Henry de la Vaulx publicado en el año 1900, dentro de la mentada revista de viajes.

Se pretende entonces en esta primera etapa acotar las fronteras de un tipo de texto que ha sido definido como un "género amorfo" o una "formación discursiva compleja", en el que se mezcla lo literario y lo (pseudo)científico, lo factual y ficcional (Beatriz Colombi, 2006). Esta naturaleza "mixta" del relato de viajes hace entonces necesario una 
aproximación interdisciplinar del mismo (Ángela Rosca, 2006), por lo que se propone aquí aportar desde el análisis estructural para avanzar en la comprensión de estos textos particulares, con una actitud de complementariedad metodológica ${ }^{2}$.

\section{Aspectos formales del corpus: Le Tour du Monde y el relato de Henry de la Vaulx}

En 1860 se funda en Francia la revista Le Tour du Monde, cuya pretensión es difundir en el seno del gran público la vasta cantidad de viajes que se realizan alrededor del globo en aquella época. En este sentido, Le Tour $d u$ Monde no es una novedad en su tiempo. Desde comienzos de siglo se publican revistas relativas a cuestiones de viaje y descubrimiento: Anales de Viaje (1807), Anales Marítimos y Coloniales (1817), Biblioteca Universal de Viajes (1833), Anuario de Viajes y Geografía (1844), Lo pintoresco (1856), y un largo etcétera (Mona Huerta, 2002). En este tipo de textos de entretención se editaban lo relatos de un sinnúmero de viajeros, quienes enviaban sus bitácoras, diarios, memorias, y variedades de textos para ser publicados.

Le Tour du Monde lleva por subtítulo "Nuevo periódico de viajes" (Nouveau journal des voyages). Lo que se propone de inmediato, a través de su caracterización de "nuevo", es una estrategia para distinguirse del resto de la literatura de viajes de la época. En la práctica, no hay una gran novedad entre lo que se da a conocer en otras revistas de la época y en Le Tour du Monde. Sin embargo, es también preciso señalar la preponderancia de Le Tour du Monde en el marco de la literatura de viajes de los siglos XIX y XX en Francia, la cual viene dada, entre otros aspectos, por el hecho de haber sido la más duradera de todas las revistas de su tipo, haber publicado más relatos, y por estar asociada a la prestigiosa editorial Hachette, guiada por el influyente político Edouard Charton.

La vasta cantidad de literatura sobre viajes responde al carácter de la época, ya que el siglo XIX, y sobre todo la segunda mitad de este, se caracterizó por la puesta en marcha de un proyecto mundial civilizatorio,

La complementariedad metodológica está dada en el hecho de que este tipo de análisis puede aportar a investigaciones de índole más bien históricas o antropológicas. Así, este estudio pretende avanzar hacia la inter y transdisciplina para el abordaje de temáticas como las que atañen. En concreto, el análisis semiodiscursivo se plantea como un método cualitativo con potencialidad de ser aplicado en el conjunto de las ciencias sociales, para una variedad de corpus y objetos teóricos (Jacques Fontanille, 2004). 
impulsado por la exploración, la urbanización y la racionalización de la vida social. Este proyecto fue gestado con al menos un siglo de anterioridad a través de los ideales de la Ilustración: la supremacía de la razón y su capacidad para beneficiar la vida del hombre. Pero no será sino hasta la segunda mitad del siglo XIX que estos ideales adquieran su mayor expresión.

El mentado editor, Edouard Charton, fue un político francés profundamente ligado a la enseñanza y la expansión del conocimiento. Le Tour du Monde no fue su primera empresa editorial con características de difusión de conocimientos sobre la alteridad, pues ya había sido fundador del Magasin pittoresque y L'Illustration. Este hombre de letras se encontraba en su época intensamente ligado al san simonismo (Grijalba, 2003) -al igual que Auguste Compte- y manifestó sus posturas ideológicas en el prólogo a la primera edición de Le Tour du Monde.

Esta revista fue publicada desde 1860 hasta el año 1914. Respecto de su periodicidad se vislumbran dos etapas: la primera entre 1860 y 1894 , en la que se publicaron 68 tomos semestralmente. La segunda etapa se cuenta desde 1894 hasta 1914, cuando se divulgó una cifra de 31 tomos que eran distribuidos anualmente. Durante la primera etapa, de periodicidad semestral, la cantidad de páginas se mantuvo constante en torno a las 430 , mientras que para el segundo periodo el número de carillas era del orden de las 640. Las publicaciones de Le Tour du Monde tuvieron un tamaño estandarizado de 31 centímetros de largo y unos 25 de ancho, lo que unido a sus 400 ó 600 páginas las hacían difíciles de almacenar y transportar a causa de su peso y tamaño, al respecto se aprecia la importancia de la literatura de viajes y los relatos de viajes en el marco de una sociedad colonial donde se justifican proyectos editoriales de alto costo de producción. La casa librera que cobijó la divulgación de Le Tour du Monde fue Hachette, editorial de gran importancia en el panorama de publicaciones de Francia y que mantiene, hasta el día de hoy, una presencia muy fuerte en el mercado de libros de ese país (Mollier, 1999).

Los trabajos publicados en Le Tour du Monde se caracterizan por la "plasticidad del relato" (Venayre 13), determinada por una escritura que mezcla lo (pseudo)científico con lo novelesco (espectacular de entretenimiento). Así, en ocasiones, hay textos con una orientación más bien descriptiva con pretensiones científicas y que renegaron de la escritura novelesca y de corte más literaria (Antoine, 2006) y otros que, por el contrario, estaban orientados hacia la escritura de espectáculo (Weber, 2006; Mazurel, 2006; Martin, 2007). 
El Viaje en Patagonia (Voyage en Patagonie) del Conde Henri de la Vaulx ${ }^{3}$ se constituye en un relato donde el contexto espacial está delimitado y responde a un área geopolítica específica y en un periodo determinado: la Patagonia chileno-argentina durante 1896. El sentido más específico del viaje y estadía de De la Vaulx, tiene que ver con la naturaleza de su empresa: recorrer las tierras, conocer de primera fuente a los indígenas y obtener cualquier vestigio físico sobre su cultura. En efecto, el periplo de De la Vaulx fue un mandato del Ministerio de Educación de la Tercera República para recoger restos óseos y vestigios de las "humanidades desaparecidas" representadas por los indígenas (Julio Vezub, 2009). En este sentido, el texto está lleno de referencias a tehuelches, patagones y araucanos, aunque sin lugar a dudas son los acercamientos a los tehuelches los que priman ${ }^{4}$. A partir de su viaje, el explorador y aventurero obtuvo fotografías y cerca de mil objetos de valor arqueológico, los que, en su mayoría, están aún almacenados en el Musée du Quai Branly en Francia (Vezub, 2009). A su retorno, de la Vaulx dictó conferencias en diversas sociedades científicas de la época en las que narraba su experiencia, y luego se dedicó al desarrollo de la aeronáutica civil. Su relato se publicó en el año 1900, correspondiendo al tomo VI de la revista (segundo periodo), y a la $17^{\text {a }}$ entrega. El texto se extiende desde la página 193 a la 264, incluyendo fotografías, grabados e ilustraciones.

\section{Marco teórico-metodológico}

El análisis estructural se ocupa de dilucidar el "funcionamiento del texto", para extraer de este las estructuras superficiales y profundas que lo constituyen (ECE 3-4). Esta búsqueda de los "constituyentes" corresponde a un estudio del plano de la inmanencia del texto, es decir (y de manera similar a una perspectiva exegética, se encarga de poner en relieve lo que el mismo texto puede aportar como elementos para su estudio (Greimas, "Las adquisiciones y los proyectos"; Jean Claude Giroud y Louis Panier, 1988). Así, el análisis estructural se distingue de las corrientes filológicas y hermenéuticas, más centrados en el contexto, datos de autoría u otras cuestiones extra-textuales, para abocarse a las intratextuales, visualizándolas como una realidad autónoma (ECE).

\footnotetext{
Nacido el 2 de abril de 1870 en Bierville, Francia, fue un viajero y explorador profundamente ligado a los avances en la aviación y los recorridos en globo y dirigibles.

Este texto fue analizado junto a otros tres por Gallegos (2010 y 2011), con miras a explicitar la representación de la alteridad indígena en la revista Le Tour du Monde a fines del siglo XIX.
} 
Para el análisis estructural el texto está constituido por, al menos, dos niveles de significación, según la modelización teórica que cada autor realice. Así, Joseph Courtes (1980), al explicar el modelo de Greimas, realiza una distinción morfo-sintáctica a nivel superficial y profundo. Del mismo modo, el ECE propone la distinción entre un componente narrativo y otro discursivo. Giroud y Panier (1988) incluyen junto al nivel narrativo y discursivo, un tercero, el semiótico o lógico semántico. Finalmente, Gerard Genette (1998) posiciona la triada de relato, narración e historia (diégesis).

Escapa a los objetivos de este trabajo dar cuenta del desarrollo genealógico evolutivo de las conceptualizaciones en el análisis estructural de los relatos. Por lo pronto, y para los fines analíticos que se exponen luego, el trabajo se aboca a hacer la distinción entre lo narrativo y lo discursivo, considerando dentro de este último nivel la inclusión de lo lógico semántico.

Así, el nivel narrativo está caracterizado por la organización de los sujetos del texto que es posible visualizar en el relato, lo que está estrechamente vinculado con los significados que se vehiculan a través de los actantes (Courtes, 1980). El relato se constituye en su estructura a través de estos y de los objetos con los que estos entran en relación (Courtes 62), ya que según Greimas es la persecución de estos objetos lo que constituye los relatos universales (Greimas, 1973). La búsqueda de estos objetos por parte de los actantes es lo que dará lugar a esquemas y programas narrativos, tal como se podrán visualizar en el siguiente apartado.

El nivel discursivo, por su parte, está compuesto por la articulación de unidades semánticas que dan coherencia al conjunto textual. Aquí, se construye un sentido a través de conceptos que entran en oposición para brindar isotopía (coherencia) a la estructura del relato. Como se verá, el nivel discursivo de los relatos de viaje del corpus está constituido por la oposición de los conceptos de civilización y barbarie que aparecen como claves de lectura y que se podrán visualizar a través de una matriz de cuadrado semiótico que da cuenta de las relaciones que se realizan entre estos conceptos.

Con el fin de responder a los objetivos propuestos, a continuación, se presenta el análisis de los dos niveles ya descritos (narrativo y discursivo), lo que permitirá visualizar la complejidad de los relatos de viajes en un sentido genérico, al tiempo que se escruta el texto particular de Henry de la Vaulx.

El análisis estructural es un modelo que se basa en la diferencia entre pares conceptuales como motor de la significación del texto. En este 
sentido, y como todo modelo teórico en todas las disciplinas, requiere de cierta competencia para ser aplicado de manera tal que los resultados sean fructíferos.

No hay "recetas" para el análisis semiótico; cada texto es un descubrimiento nuevo y necesita un proceso de aproximación original, pero siempre a partir de la observación de los elementos constitutivos del texto, proponiendo hipótesis sobre la organización de la significación (formuladas de la manera más rigurosa posible, apelando a los elementos y a los modelos de la teoría), y procediendo a una verificación de esta hipótesis sobre el texto mismo. La semiótica se presenta así como una lectura de los textos atenta y controlada. (Giroud y Panier 5)

Esta lectura atenta y controlada que representa la semiótica, se constituye como una especie de síntesis que se encuentra a medio camino entre, por un lado, los análisis con la libertad de la crítica literaria, y por el otro, los modelos mecánicos operacionalizados a través de matrices estáticas que, como si fuesen recetas, pretenden ser repetidos una y otra vez para consentir una visión de ciencia que cada vez con mayor fuerza se complace en exaltar una visión "cientificista", con el fin de llenar en el seno de las ciencias sociales las exigencias de legitimidad provenientes de otras disciplinas con pretensiones objetivistas hegemónicas. En este sentido, el análisis estructural puede ser visto como una suerte de oposición, o tercera vía, a esta visión "cientificista".

\section{Análisis del componente narrativo}

El análisis de los relatos de viajes extraídos de Le Tour du Monde dan cuenta de un esquema narrativo basado en la sucesión de etapas. Según Greimas (1980) existe recurrencia en los textos narrativos en cuanto a la sucesión de tres pruebas que orientan y articulan los textos: la prueba cualificante, la prueba decisiva y la prueba glorificante.

La sucesión de estos estadios hace necesario considerar el dispositivo textual-sintagmático como poseedor de un sentido y de una dirección, es decir, con una estructura subyacente que es preciso revelar e interpretar en la lectura semiótica (Greimas 9).

Los tres estadios del relato antes señalados pueden ser asociados al inicio, desarrollo y final de la trama, siguiendo el esquema típico que se 
asemejaría a una curva normal. La prueba cualificante en este caso de estudio se encuentra presupuesta al inicio del texto: un relato de viajes, de descripciones de lugares y personas lejanas supone el hecho de que quién efectúa el viaje se encuentra cualificado para hacerlo. Dentro de la prueba cualificante como elemento constitutivo de la enunciación se encuentran, por ejemplo, las justificaciones de por qué se realiza el viaje: “[...] como ya le he dicho que mis locuras tienen especialmente un objetivo antropológico, él me señala que hace apenas dos meses vio enterrar un Tehuelche que los indígenas consideraban como un gigante. Él me promete indicarme mañana el lugar exacto de la sepultura." (subrayado agregado; de la Vaulx 240).

De esta forma, el viajero se encuentra desde el inicio de su periplo validado, es decir, cualificado para emprender el "objetivo antropológico" de su travesía. No obstante, esto no impide que el héroe tenga que pasar por incomodidades o situaciones que ponen a prueba su capacidad y competencia. Se manifiesta entonces la prueba decisiva, en la que el héroe-viajero puede verse superado en ocasiones por la naturaleza o los azarosos avatares de su itinerario, o por el simple hecho de encontrarse lejos de la querida y siempre añorada civilización.

Sin embargo, son las escenas trágicas y rimbombantes las que predominan en este tipo de textos. Es preciso recalcar que es la tónica de aventura lo que prevalece en el relato, pues la expansión de la civilización y la modernidad están inmersas en un aura de romanticismo y finales felices (Bremond, 1964). Las dificultades entonces aparecen como condición necesaria para la exaltación final del héroe-viajero. Así, son comunes las referencias a pérdidas momentáneas del rumbo, grandes tormentas que es necesario enfrentar, cuasi naufragios, enfermedades pasajeras, inundaciones que afectan la integridad física y material de los viajeros, entre otras situaciones como estas.

La "inundación en la pampa" (De la Vaulx 213), por ejemplo, será objeto de un sufrido relato por parte de De la Vaulx, donde mostrará todos los flagelos y condiciones adversas que debe enfrentar cualquier hombre que se aventure en una empresa expedicionaria. Sin embargo, todas estas situaciones (pruebas decisivas) serán superadas luego por la supremacía de la glorificación del actante, donde todo el sufrimiento y penurias pasadas se olvidan y quedan relegadas cuando se aprecian los frutos de la labor de los exploradores, colonos o cualquier europeo que se haya aventurado en estas recónditas tierras. 
Además de la sucesión de pruebas antes descrita, el viajero se articula dentro de la estructura inmanente del texto como un sujeto actante con una función textual específica y siempre orientada hacia un objeto (Bal, 2001):

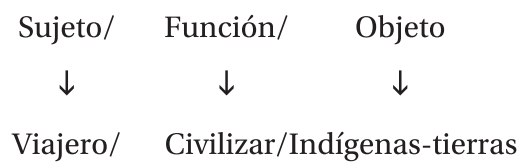

La función del actante (sujeto-viajero) no remitiría sólo a civilizar; se pueden señalar un sinnúmero de otras funciones, sin embargo, la de civilizar es la que se considera más enraizada en el nivel profundo de significación del texto, y que tiene que ver con el imaginario de la época. Se muestra ahora un último ejemplo extraído de los párrafos finales del relato de De la Vaulx, y que grafica la finalización del relato con la prueba glorificante, que da sentido a toda la fábula.

El clima vigorizante que reina en estos parajes es particularmente conveniente a nuestras razas de la Europa septentrional, y no es quizás muy lejano el día en que estos inmensos territorios, hoy desiertos e incultos, serán una fuente de riquezas prodigiosas para el gobierno que sepa imponer su autoridad y generar un torrente migratorio. Creo haber indicado suficientemente en esta obra los puntos en los que se podría encausar la actividad de los colonos y pienso haber dado una percepción verídica de los hábitos y costumbres de los habitantes de las tierras australes. (De la Vaulx 264)

De esta forma, el programa narrativo principal (PN) que guiará al sujeto/actante viajero (S1) en los relatos será el de un hacer (H) que a través de su performance $(v)$ cambiará el estado de disyunción $(\exists)$ que presenta el sujeto indígena (S2) con el objeto de la civilización (O1), con el fin de obrar un resultado $\rightarrow$ ) que llevará al indígena (S2) a estar ahora conjunto $(\wedge)$ con el objeto civilización $(\mathrm{O} 1)$ :

$$
\mathrm{PN}: \mathrm{H}(\mathrm{S} 1) \rightrightarrows[(\mathrm{S} 2 \vee \mathrm{O} 1) \rightarrow(\mathrm{S} 2 \wedge \mathrm{O} 1)]
$$

Evidentemente, este programa narrativo principal se lleva a cabo mediante una serie de otros (sub)programas narrativos. A continuación se presenta uno de ellos, a través de un pasaje del texto que cumple con los criterios de clausura operacional. Luego de la descripción narrativa de este fragmento, se pasará al análisis del componente discursivo. 
8 de Diciembre. - Ya es de mañana y todos los hombres de la tribu llegan a caballo delante del toldo del cacique. Un círculo se forma y Sakamata informa a sus seguidores que yo he venido a la región para visitarlos y traer saludos de sus hermanos blancos. Entonces expreso el deseo de tomar algunas fotografías con el fin de poder llevarlas a mi país y mostrar a mis compatriotas los rasgos de mis nuevos amigos de las tierras del Sur. Los pampas y los araucanos están ansiosos por ser fotografiados, pero un viejo Tehuelche, padre de cuatro grandes jóvenes, se muestra rebelde.

“¿Por qué dejar nuestras figuras a este joven hombre, dice él, que es quizás un brujo y que podrá por lo tanto hacernos brujería? No podemos existir en dos lugares a la vez, y si nuestra imagen se encuentra representada en un papel, es nuestra muerte segura."

Habiendo razonado con el viejo Tehuelche, este se muestra intratable; de pronto, es apoyado por sus cuatro nietos. Uno de ellos ya se ha quitado las boleadoras de su cintura y me observa con un aire amenazante. Yo apelo a la caña (agua de vida) como seguridad, y rápidamente, bajo la influencia del alcohol, los Tehuelches se vuelven más dóciles. Le entrego varias copas colmadas y son completamente sumisos. Me alisto ahora a fotografiarlos. (De la Vaulx 238)

En este texto se aprecia que la primera condición es un estado de disyunción de objeto: el viajero quiere fotografiar a los indígenas, pero uno de estos se opone; así el sujeto viajero (S1) queda disyunto (v) del objeto fotografía $(\mathrm{O} 2)[(\mathrm{S} 1 \vee \mathrm{O} 2)]$.

De este modo, el viajero como sujeto operador comienza una performance con el fin de lograr la transformación del estado de disyunción, para lo cual actúa conforme a sus competencias y con los medios de los que dispone. En este caso, lo hace a través del uso del alcohol (O3) y aprovecha la separación que hay entre este (O3) y los indígenas (S2):

$$
\mathrm{PN} 1 \mathrm{H}\left(\mathrm{S}_{1}\right) \rightrightarrows\left[\left(\mathrm{S}_{2} \vee \mathrm{O}_{3}\right) \rightarrow\left(\mathrm{S}_{2} \wedge \mathrm{O}_{3}\right)\right] \infty \mathrm{H}\left(\mathrm{S}_{2}\right) \rightrightarrows\left[\left(\mathrm{S}_{1} \vee \mathrm{O}_{2}\right) \rightarrow\left(\mathrm{S}_{1} \wedge \mathrm{O}_{2}\right)\right]
$$

Se visualiza que en este programa narrativo (PN1) el hacer $(\mathrm{H})$ del viajero (S1) está orientado a transformar mediante su performance $(\exists)$ la 
carencia-disyunción ( $v$ ) entre el indígena (S2) y el alcohol como objeto de su deseo (O3), con el fin de llevarlos a un estado de conjunción (S2^ O3). Este hacer tiene una relación recíproca $(\infty)$ con el hacer $(\mathrm{H})$ del indígena (S2) quien, al estar en conjunción con el alcohol, va a transformar el estado de disyunción entre el sujeto viajero (S1) y las fotografías, que ahora pasan a estar conjuntos.

\section{Análisis del componente discursivo y lógico-semántico}

Corresponde en este apartado revisar los valores temáticos fundamentales que se ponen en funcionamiento en la estructura discursiva del relato de viajes, junto con los recorridos figurativos que realizan los actores.

El sentido de los textos se construye a través de conceptos que entran en oposición para brindar isotopía (coherencia) a la estructura del relato, esta es la premisa sobre la que se funda el análisis discursivo en el marco del análisis estructural de textos. Así, la diferencia que otorga el sentido a los relatos de viaje está fundada en los valores temáticos de civilización y barbarie, donde la civilización aparece representada por el viajero, y la barbarie por los indígenas que encuentra a su paso y las tierras que explora.

Los valores temáticos básicos (civilización/barbarie) quedan articulados en una matriz de cuadrado semiótico de la siguiente manera:

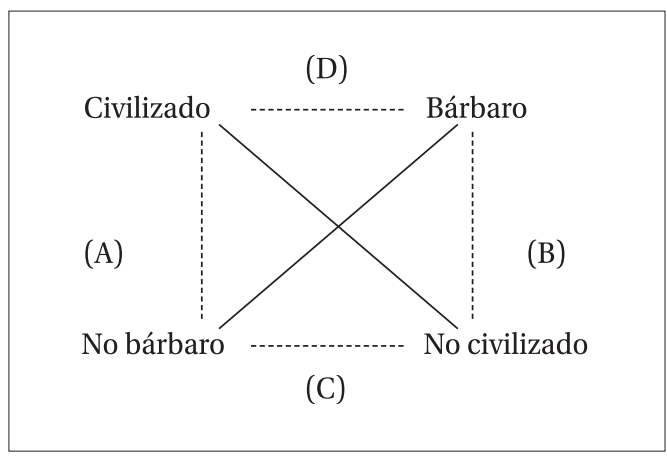

Imagen 1. Cuadrado semiótico: valores temáticos.

Las claves de lectura civilización/barbarie se agrupan en el cuadrado anterior, donde lo civilizado-no bárbaro (A), se opone a lo bárbaro-no civilizado (B). Sin embargo, surgen dos nuevos tipos de relaciones (C) y (D) de las que es preciso dar cuenta, con el fin de mostrar que los valores temáticos y recorridos figurativos escapan a la reduccionista dicotomía 
civilización-barbarie y se presentan nuevas modalidades interesantes para el estudio.

La distinción entre lo civilizado y lo bárbaro aparece entonces de manera claramente diferenciada en los textos:

Mi guía tiene razón. Estos campamentos han permanecido intactos; se creería que el tiempo que ha pasado sobre estas cosas ha dudado en borrar los últimos vestigios de una humanidad desaparecida. (De la Vaulx 197)

$[\ldots]$

Elevo los ojos a mi lado y siento, debo admitirlo, una mezcla de sorpresa y horror observando la cara de los Indios cubierta de sangre, las manos rojas, tragando con voracidad las entrañas aún palpitantes de una bestia que apenas viene de expirar. Es ahí, que veo en todo su hedor el salvajismo de esas tribus primitivas. (De la Vaulx 224)

Esta "humanidad desaparecida" (B) es la que manifiesta el salvajismo y la barbarie de los indígenas, y que debe dar lugar a una "humanidad civilizada" (A). Frente a estas dos realidades excluyentes se presenta una especie de punto intermedio donde no se es ni civilizado, ni bárbaro (C). Este aspecto estaría representado en el texto por los indígenas a los que se les ha intentado vaciar de su cultura a través de la escuela, el trabajo u otras formas que apuntan a la aculturación. Se trataría entonces de "semi-civilizados" (C), no del todo bárbaros, pero tampoco del todo representantes de la civilización: “[...] Me dirijo a visitar esas tiendas: "rucas". A mi llegada, soy más bien mal recibido por los Indios que las habitan y que, en un estado de semi-civilización, son tanto más desconfiados frente a los blancos" (De la Vaulx 217)

Es interesante notar que una parte de las conceptualizaciones de barbarie que realiza el enunciatario en relación con los indígenas se basa en el uso y abuso que hacen estos del alcohol. Así, al participar de una fiesta al poco tiempo de iniciar su travesía, de la Vaulx señala:

En tanto que duran estas danzas, las conversaciones que se intercambian entre los asistentes son más bien ligeras. El libertinaje se desata libremente. [...] En ese momento el alcohol ha producido ya su efecto y mientras más avance la fiesta, más repugnante será. [...] Yo regreso a la tienda donde habito y me recuesto sobre mi cama para intentar dormir. Por momentos 
un suspiro, lamentos o gritos llegan a mi oído. Se trata de algún Indio torturado por el alcohol [...]. (subrayado agregado; De la Vaulx 228)

El alcohol es así el causante (al menos en parte) de la repugnancia y de la barbarie de los indígenas. Esto lleva a visualizar la contradicción del viajero quien, al avanzar en su periplo, no dudará en utilizar la caña o agua de vida como medio para obtener sus fines, tal y como ya se ha mostrado en el programa narrativo (PN1).

Se aprecia entonces la contradicción civilizatoria al considerar el alcohol como elemento de barbarie, pero, al mismo tiempo, usarlo para lograr sus fines. Esta situación contradictoria se reitera en otras ocasiones sin ser parte de una racionalización por parte del supuestamente "civilizado".

Un día, estando de visita donde la vieja Thomassin, me observaba con mirada iracunda, desde que yo había sometido a su paisano a la cocina macabra que ya he señalado. Al principio se me recibe muy fríamente, pero la caña derrite rápidamente el hielo que se levantaba entre la vieja India y yo -que dichosa invención que es el alcohol para un explorador. (De la Vaulx 242)

La idea de "dichosa invención que es el alcohol para el explorador", choca nuevamente con el concepto de que el alcohol no es un beneficio para los "bárbaros": "Observando este horrible espectáculo y siguiendo los ojos rojos que proyectan las fogatas sobre la pampa, me lamento de la desgracia de que la civilización les haya dotado de alcohol" (De la Vaulx 251).

Así, aparece el último componente del cuadrado semiótico, que es el lugar en donde se hallan en relación los elementos contradictorios de la civilización y la barbarie (D). El uso del alcohol aparece como la muestra de esta contradicción, que hacia el final del relato el sujeto/ actante viajero, logra identificar: "Regreso encantado de los resultados de mi misión. He completado a caballo un trayecto de 5000 kilómetros y he entregado documentos inéditos sobre estas razas de la América Austral, razas que tienden a desaparecer del globo bajo la presión civilizadora y bárbara del alcohol." (De la Vaulx 264). De modo que se evidencian en el relato de los valores temáticos que emergen de la construcción del cuadrado semiótico a partir de la dicotomía principal de civilizados y bárbaros, y que se resume en el siguiente cuadro. 


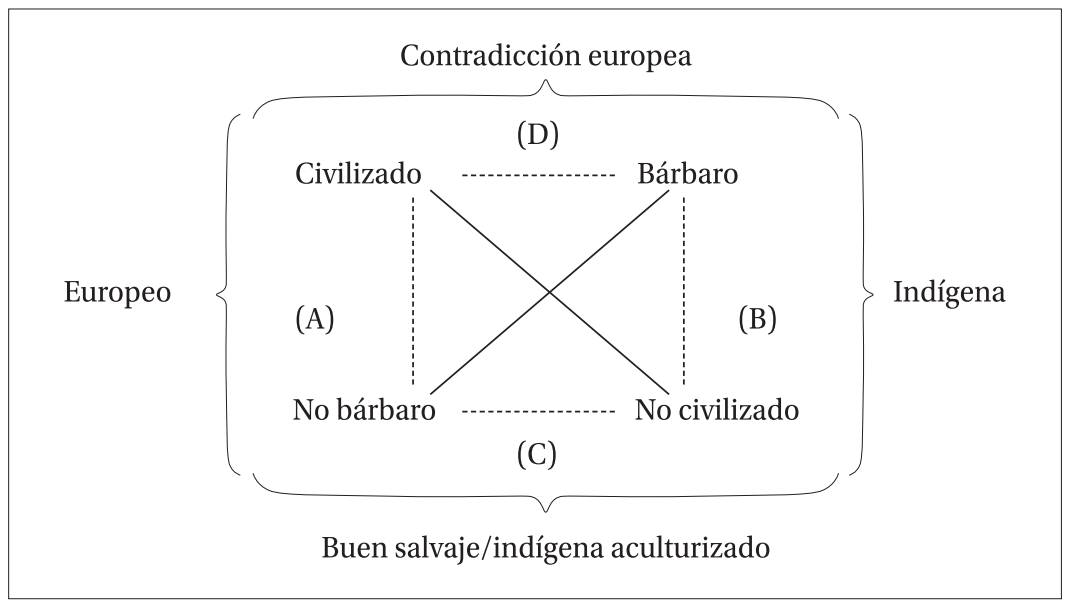

Imagen 2. Cuadrado semiótico: relaciones lógicas entre conceptos.

Este cuadro ayuda también a visualizar la forma en que aparece la contradicción europea (D) en el relato. Así, es posible hablar de una deixis positiva (o disfórica) y de una negativa (o eufórica).

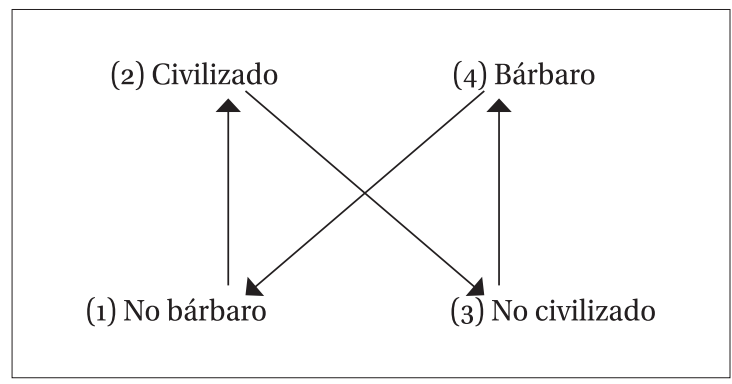

Imagen 3. Deixis y recorridos figurativos.

La deixis positiva se representa mediante el programa narrativo principal, que ya se ha revisado dentro del componente narrativo, donde se busca que el No civilizado-bárbaro (3) y (4) pase a un estado de No barbarie-civilización (1) y (2). Esto representa el "ideal" de lógica narrativa del relato de viajes, en el sentido de que el texto en el seno de la revista estudiada busca dar cuenta de los procesos de avance de la civilización.

Por otra parte, la deixis negativa está representada por el paso de lo No bárbaro-civilizado (1) y (2), hacia lo No civilizado-bárbaro (3) y (4). Este recorrido figurativo representa las fases por las que pasa el sujeto 
viajero, quien, como ya se ha visto, pasa a un estado de contradicción al utilizar un elemento disuasivo (el alcohol) que él mismo reconoce como elemento de barbarie, pero que, paradójicamente, es introducido por la civilización. Aparece entonces una disonancia evidente entre la lógica ideal del relato (deixis positiva) y la lógica real del texto (deixis negativa), lo que se expresa como un corolario trágico: la anhelada expansión de la civilización viene a transformarse en más barbarie. El que se decía “civilizado" se da cuenta de que en realidad es "bárbaro".

Las deixis arriba descritas corresponden, por una parte, a una deixis ideal (deixis positiva), que muestra el ideal civilizador de la performancia del sujeto-viajero y, por otro lado, a una deixis real (deixis negativa), que es la que concretamente ejecuta el sujeto viajero. De esta forma, es posible describir los papeles actanciales que se desarrollan en la deixis negativa/real:

Imagen 4. Resumen de la deixis. Tomado de Giroud y Panier, 51.

\begin{tabular}{|c|c|c|c|}
\hline Manipulación & Competencia & Performancia & Sanción \\
\hline $\begin{array}{l}\text { Hacer hacer } \\
\text {-destinatario } \\
\text {-sujeto }\end{array}$ & $\begin{array}{l}\text { Ser del hacer } \\
\text {-sujeto } \\
\text {-condiciones del } \\
\text { hacer }\end{array}$ & $\begin{array}{l}\text { Hacer ser } \\
\text {-sujeto operador } \\
\text {-transformación } \\
\quad \text { (sujeto de estado; } \\
\text { objeto-valor) }\end{array}$ & $\begin{array}{l}\text { Ser del ser } \\
\text {-destinatario } \\
\text { (epistémico) } \\
\text {-sujeto operador }\end{array}$ \\
\hline "Persuasión" & $\begin{array}{l}\text { "Adquisición de } \\
\text { competencia" }\end{array}$ & $\begin{array}{l}\text { "Acción de } \\
\text { transformación" }\end{array}$ & "Evaluación" \\
\hline
\end{tabular}

Así, es posible visualizar una linealidad en el desarrollo del papel actancial que realiza el sujeto-viajero, al pasar por una etapa de manipulación (querer convencer a los indígenas de poder fotografiarlos), luego una etapa de competencia, donde para lograr su hacer (fotografiar) apela a la utilización del alcohol para hacerlos "más dóciles" (De la Vaulx 238). A partir de ahí, emerge la performancia como elemento que concreta la transformación, para luego pasar a una etapa de sanción en que se evalúa el accionar. Esta evaluación, a su vez, conducirá en este caso a una sanción negativa, a través de la cual el sujeto logra visualizar, al menos en parte, la contradicción de su "misión civilizadora", expresada en "la presión civilizadora y bárbara del alcohol" (De la Vaulx 264). 
En rigor, los papeles actanciales corresponden al componente narrativo de los relatos (Giroud y Panier, 1988). Asimismo, Courtes (1980) categoriza las formas de querer/saber/poder-hacer como parte de la "modalización sintáctica”. Sin embargo, se han incluido en esta sección por ser ilustrativos de los regímenes discursivos, y porque, además, los procesos narrativo y discursivo forman parte de un todo cuya división no es canónica, sino práctica-metodológica con el fin de entender el funcionamiento del texto.

\section{Conclusiones}

A partir de lo desarrollado a lo largo del presente trabajo es posible extraer algunas conclusiones generales respecto de los elementos narrativos y discursivos presentes en algunos relatos de viaje. Así, genéricamente es posible señalar que en estos textos se cumple el esquema narrativo propuesto por Greimas (1980), consistente en la sucesión de pruebas. Al mismo tiempo, se aprecia que el programa narrativo principal de los relatos de viaje, sobre todo los decimonónicos como en el caso de los publicados en Le Tour du Monde, pone en una situación de disyunción a los sujetos indígenas del objeto civilización, donde el sujeto-viajero se propone llevar la civilización a los indígenas.

En términos de caracterización discursiva, genéricamente estos relatos de viaje posicionan la dicotomía civilización/barbarie como el fundamento lógico-semántico que estructura las relaciones a lo largo de los trabajos. Con respecto al análisis del texto específico de Henry de la Vaulx, se ha dado cuenta de cómo la matriz cuadrado semiótico es del todo útil para caracterizar situaciones intermedias que escapan a la diferenciación exclusiva de civilización y barbarie. Se ha mostrado cómo estos conceptos se mezclan para dar forma a valores temáticos (Giroud y Panier 17) que incluyen situaciones discursivas donde se manifiesta una hibridación entre lo civilizado y lo bárbaro.

En cuanto a lo epistémico-metodológico, el análisis estructural propuesto no pretende ser exclusivo ni canonizado; por el contrario, puede ser complementado con otro tipo de análisis con el fin de dar cuenta de manera más profunda de diversos objetos de estudios, para llegar a una comprensión abarcadora de distintas problemáticas de las ciencias en general, particularmente las ciencias sociales. 
Así mismo, el análisis estructural se manifiesta como una metodología pertinente para el análisis de diversos textos y relatos. Será tarea de académicos e investigadores revisitar sus conceptos, adecuarlos y si es necesario transformarlos, siguiendo con el carácter acumulativo y evolutivo del conocimiento. En este sentido, este tipo de análisis tiene potencialidad de constituirse en una herramienta útil para sobrepasar los modelos extremadamente mecánicos y técnicos, como los propuestos por Genette (1998) y Bal (2001), y al mismo tiempo no caer en la lógica de crítica literaria, sin posibilidad de replicabilidad ni de corroboración de hipótesis de lectura.

El análisis estructural se manifiesta entonces como un punto de equilibrio, donde el modelo puede ser revisado, discutido, comprobado y superado. Finalmente, el modelo no funciona sino en relación con las capacidades analíticas de quien lo opera, con la asertividad y agudeza con la que se eligen las isotopías según las que actúan determinadas oposiciones fundantes. Greimas posicionaba su propuesta como un procedimiento científico, porque: 1) es un método coherente: todos los términos empleados se interdefinen entre sí; 2) aboca a una transmisión del saber, es universal al menos en un cierto espacio cultural; 3) obedece al principio de la inmanencia (ECE 54).

Más allá de la cientificidad o no del método, lo cierto es que se trata de un modelo útil, dinámico y con posibilidades de ser adaptado para distintos tipos de textos y situaciones, permitiendo visualizar elementos novedosos, como los ya mostrado en relación con las nuevas posibilidades o "entre medios" que se abren entre la dicotomía civilización/barbarie.

\section{Referencias bibliográficas}

Antoine, Philippe. “Ceci n'est pas un livre. Le récit du voyage et le refus de la littérature”. Sociétés et Représentations, no. 21, abr. 2006, pp. 45-58.

Bal, Mieke. Teoría de la Narrativa (una introducción a la narratología). Madrid, Editorial Cátedra, 2001.

Barthes, Roland. "Introduction à l'analyse structurale des récits". Communications, no. 8. 1966, pp. 1-27.

Bremond, Claude. "La logique des posibles narratifs". Communications, no. 8,1966 , pp. 60-76. 
"Le message narratif". Communications, no. 4, 1964, pp. 4-32.

Colombi, Beatriz. "El viaje y su relato". Latinoamérica. Revista de Estudios Latinoamericanos, no. 43, 2006, pp. 11-35.

Courtes, Joseph. Introducción a la semiótica narrativa y discursiva. Metodología y aplicación. Buenos Aires, Ed. Librería Hachette S.A., 1980.

De La Vaulx, Henry. "Voyage en Patagonie". Le Tour du Monde. Trad. Eduardo Gallegos. Nouvelle série, $6^{\mathrm{e}}$ année, 1900, pp. 193-264. ECE (Equipe Cahiers Evangile). Iniciación en el análisis estructural. Navarra, Editorial Verbo Divino, 1980.

Fontanille, Jacques. Sémiotique des textes et des discours. Dictionnaire des méthodes qualitatives en sciences humaines. Ed. Alex Mucchielli. Paris, Armand Colin, 2004.

Gallegos, Eduardo y Otazo, Jaime. "Los Mapuches bajo la mirada de un viajero francés de fines del siglo XIX. El relato del viaje a Chile de M. J. Cordemoy en la revista Le Tour du Monde (Paris, 1896 y 1898)". Revista de Lenguas y Literatura Mapuche, no. 15, 2011, pp. 111-130.

Gallegos, Eduardo. “Representación de la alteridad indígena de la América Meridional en los relatos de tres viajeros franceses de fines del siglo XIX publicados en la revista Le Tour du Monde". Tesis para optar al grado de Licenciado en Comunicación Social. Bajo la dirección de Dr. Jaime Otazo. Universidad de La Frontera. Temuco. Chile. 2011.

"Viajeros europeos en la América Meridional a fines del s.XIX. La representación de la alteridad indígena en la revista Le Tour du Monde.". Tesina para optar a Certificat d' Etudes Politiques. Bajo la dirección de Dra. Ximena Obregón. Institute d'Etudes Politiques. Rennes, Francia, 2010.

Genette, Gerard. Nuevo discurso del relato. Madrid, Editorial Cátedra, 1998.

Giroud, Jean Claude y Panier, Louis. Semiótica. Navarra, Editorial Verbo Divino, 1988.

Greimas, Algirdas. "Las adquisiciones y los proyectos". Introducción a la semiótica narrativa y discursiva. Metodología y aplicación. Ed. Joseph Courtes. Buenos Aires, Ed. Librería Hachette S.A., 1980, pp. 5-25. 
"Un problème de sémiotique narrative: les objets de valeur". Langages, no. 31, 8 année, 1973, pp. 13-35.

Grijalba, Covadonga. "Viajar contar, soñar... con Le Tour du Monde". El texto como encrucijada: estudios franceses y francófonos. Coord. Ignacio Iñarrea y María Jesús Salinero España, Ediciones Universidad de la Rioja, 2008, pp. 71-84.

Huerta, Mona. "Le voyage aux Amériques et les revues savantes françaises au XIXe siécle". A la redécouverte des Amériques. Les voyageurs européens au siècle des indépendances. Eds. Michel Bertrand et Laurent Vidal. Toulousse, Presses Universitaires du Mirail, 2002, pp. 73-93.

Martin, Marc. "Le voyage du grand reporter, de la fin du XIXe siècle aux années 1930". Les temps des Médias, no. 8, 2007, pp. 118-129.

Mazurel, Hervé. "La poesie dans la construction d'une histoire culturelle du voyage autour du pelerinage de childeharold de Lord Byron". Sociétés et Représentations, no. 21, avril, 2006, pp.191-211.

Mollier, Jean-Yves. "Les mutations de l'espace editorial français du XVIIIe au XXe siècle". Actes de la recherche en sciences sociale, Vol. 126-127, 1999, pp. 29-38.

Otazo, Jaime y Gallegos, Eduardo. "La frontera infranqueable: La araucanía en los relatos de viaje de dos ingenieros francófonos en el Chile de fines del siglo XIX (Gustave Verniory y Camille Jacob de Cordemoy)". Revista S, Vol. 5, 2011, pp. 127-144.

Propp, Vladimir. Morfología del cuento: las transformaciones de los cuentos maravillosos. Madrid, Fundamentos, 1981.

Rosca, Angela. La tipología de los discursos en los libros de viajes de Mihái Ticán Rumano. Tesis doctoral en Filología Románica. Bajo la dirección de Eugenia Popeanga. Universidad Complutense de Madrid, 2006.

Todorov, Zvetan. Literatura y significación. Barcelona, Editorial Planeta, 1971.

Venayre, Sylvain. "Pour une histoire culturelle du voyage au XIX siècle". Sociétés et Représentations, no. 21, 2006, pp. 5-21.

Vezub, Julio. “Henry de La Vaulx en Patagonia (1896 - 1897): la historicidad escindida de la antropología colonial y la captura de corpus y cuerpos". Nuevo Mundo. Mundos Nuevos, nov. 2009. [En línea]. 
Weber, Abbe-Gaëlle. "Le genre romanesque du récit de voyage scientifique au XIX siècle". Sociétés et Représentations, no. 21, avril, 2006, pp. 59-77. 